\title{
Melkersson-Rosenthal Syndrome Complicated with Facial Hemiespasm and Intracranial Hypertension
}

ISSN: 2640-9208

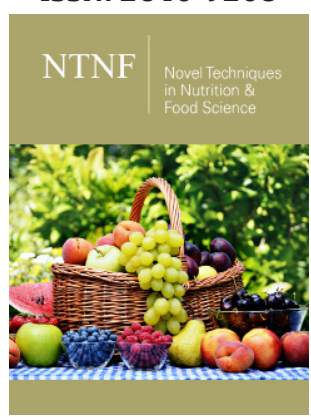

*Corresponding author: Elis Penteado Arantes, Department of Medicine, Brasil

Submission: 制September 11, 2020

Published: 漹October 09, 2020

Volume 5 - Issue 2

How to cite this article: Elis Penteado Arantes, Giuliana Vieira Pretti, Soo Yang Lee, Fabiana Penedo Leme. MelkerssonRosenthal Syndrome Complicated with Facial Hemiespasm and Intracranial Hypertension. Nov Tech Nutri Food Sci. 5(2). NTNF. 000609. 2020

DOI: 10.31031/NTNF.2020.05.000609

Copyright@ Elis Penteado Arantes. This article is distributed under the terms of the Creative Commons Attribution 4.0 International License, which permits unrestricted use and redistribution provided that the original author and source are credited.

\author{
Elis Penteado Arantes ${ }^{1 *}$, Giuliana Vieira Pretti ${ }^{1}$, Soo Yang Lee ${ }^{2}$ and Fabiana \\ Penedo Leme ${ }^{2}$ \\ ${ }^{1}$ Department of Medicine, Brasil \\ ${ }^{2}$ Department of Neurology, Brasil
}

\begin{abstract}
Since it was first described in 1928 by neurologist Melkersson [1], and complemented in 1931 by Rosenthal C [2], the Melkersson [1] and Rosenthal [2] Syndrome (SMR) has been shown to be a rare disorder and still in need of specific treatment [3,4]. We describe the case of a young patient, who at 23 years old had the first episode of peripheral facial paralysis on the right. At the time, it was conducted in a protocol manner, with prednisone, paracetamol and eye care, as well as pertinent physiotherapy. There was an improvement in facial asymmetry, when in 2006 she presented a new peripheral facial paralysis, this time on the left, which was conducted in a similar way. Then, she presented 2 more episodes of facial paralysis in the interval of 3 years, already with aesthetic sequelae. In 2009, in the $5^{\text {th }}$ episode of paralysis, she associated facial edema and cheilitis, when biopsy of the upper eyelid was requested, which was unspecific. In 2012, after the $8^{\text {th }}$ facial paralysis, she underwent a new biopsy, in which an inflammatory infiltrate was demonstrated, consistent with clinical suspicion of SMR. Imaging exams (skull resonance and angioresonance), face electroneuromyography - for prognosis, and CSF study, without abnormalities, were performed. That year she began to experience involuntary and rhythmic contractions of the orbicularis musculature of the eyes and mouth on the right, in addition to risory and platysma, featuring facial hemispasm, treated every 4 to 6 months with 100 IU Onabotulinum. Throughout the treatment period, alternating use of $10 \mathrm{mg}$ prednisone with deflazacort $6 \mathrm{mg}$, and in 2019 , due to persistent headache, she underwent a new resonance with arterial and venous cranial angioresonance, which brought elements suggestive of Intracranial Hypertension (IH). Currently, the patient is undergoing surgical programming for facial nerve decompression bilaterally and undergoing treatment for $\mathrm{IH}$.
\end{abstract}

Keywords: Facial hemispasm; Cheilitis; Intracranial hypertension; Facial edema; Facial paralysis

\section{Introduction}

Facial paralysis and edema were first described by Melkersson [1]. Three years later, Rosenthal associated these symptoms with a cleft tongue [2]. his triad was called MelkerssonRosenthal syndrome by Lüscher [5]. However, some authors argue that the complete syndrome is rare, being the most common monosymptomatic or sequential presentation [6]. The Melkersson-Rosenthal syndrome has an estimated incidence of $0.08 \%$ and an unknown etiology [7]. According to Ang et al. [8], there is a slight predilection for the female sex, usually around the second decade of life [8], there is no racial predilection [9] and there are no reports that associate S.M.R with malignant transformation [10]. The syndrome has a classic triad, consisting of recurrent or persistent orofacial edema, recurrent facial paralysis and plicate or scrotal tongue, which occurs very rarely [11]. Frequently, SMR manifests itself in its oligosymptomatic (combination of 2 signs) or monosymptomatic forms, such as Miescher's granulomatous macroqueilitis, which can be a diagnostic difficulty $[9,11]$.

The first manifestation is, predominantly, acute diffuse edema involving the upper lip (75$100 \%$ ), and less the lower lip, which completely regresses in hours or days [11]. 0 Edema develops through outbreaks, sometimes unilateral, for days or weeks, at irregular intervals, with an increase in volume that can reach two to three times the normal size until a permanent infiltration is established [11]. The involvement of the intraoral mucosa may also appear, 
namely edema of the gums, palate, oral, sublingual mucosa, tongue and even pharynx and larynx $[8,11]$.

Peripheral facial paralysis occurs as an initial manifestation in 30 to $50 \%$ of patients with SMR. Clinically, it is indistinguishable from Bell's Palsy [12], usually having a sudden onset or, rarely, gradually over 24 to 48 hours, with complete resolution after a few weeks [11]. Although at first it is intermittent, it can become persistent [11]. Facial paralysis often develops after granulomatous cheilitis, but there are reports of cases in which it precedes it for several months or years or occurs simultaneously [11]. In most cases it is unilateral, corresponding (although not always) alongside orofacial infiltration and, rarely, it is bilateral, it can be partial or complete [11].

The diffusely fissured tongue (plicated or scrotal tongue) is described in 20 to $60 \%$ of patients with SMR and may be associated with a burning sensation, edema, loss of taste and decreased salivary secretion [11]. Some signs and symptoms are defined as minor criteria that are also part of the Melkersson-Rosenthal syndrome [13]. The involvement of other cranial pairs, migraine and dysfunctions of the salivary and lacrimal glands and pupillary motricity constitute these minor criteria, in addition to the presence of hyperhidrosis, hyperacusis, acroparesthesia, epiphora, hypergeusia and multiple ophthalmological findings such as lagophthalmos, keratitis by exposure, blepharocalasia, retrobulbar neuritis, anomaly of the retinal veins and paralysis of the medial rectus muscle.

The histopathology of cutaneous or mucous biopsies in patients with SMR may show, in an initial phase, only a nonspecific lympho-plasmacytic and histiocytic infiltrate, predominantly perivascular, which may represent the primordial stage of granuloma formation [11]. However, even in complete forms, this granulomatous infiltrate is not observed in more than half of the cases and its absence should not exclude the diagnosis of SMR [11]. The involvement of unusual locations in the orofacial region and the presence of minor isolated manifestations often precede the development of typical clinical manifestations. This fact, associated with the underestimation of symptoms by the patient himself, makes, in most cases, difficult to make a correct diagnosis early or even probable $[4,11]$. This way, SMR has been shown to be a rare disorder and still in need of specific treatment $[3,4]$. In the present report, we describe a case not yet described in the literature, in which the patient initially treated as Bell's Palsy, evolved with facial edema, cheilitis, right facial hemispasm and Idiopathic Intracranial Hypertension Syndrome (IIH).

\section{Case Description}

SSL, 23 years old, domiciled in São Mateus, ES, presented peripheral facial paralysis of the right hemiface in 2005 and was treated as Bell's Palsy with corticosteroid and analgesic. There was an improvement in asymmetry on the face, when in 2006 she presented a new paralysis, this time on the left, which was conducted in a similar way. Then, she presented 2 more episodes in the interval of 3 years, already with aesthetic sequelae. In 2009, in the $5^{\text {th }}$ episode of paralysis, she associated facial edema and cheilitis, when the SMR hypothesis was suggested, but with an upper eyelid biopsy that was unspecific. In the period from 2009 to 2012, the patient had conductive and sensorineural hearing loss in her left ear and had several episodes of pain in the face refractory to clinical treatment that made her unable to work.

In 2012, after the $8^{\text {th }}$ facial paralysis, she underwent a new biopsy, this time showing an inflammatory infiltrate consistent with clinical suspicion. Arterial resonance and angioresonance of the skull without abnormal findings at the time, electroneuromyography of the face-for prognosis, which revealed signs of neuropathic involvement of the right and left facial nerves with moderate/ moderately severe axonal injury data, slightly more intense on the left, and a CSF study without abnormalities. Later that year, she evolved with facial hemispasm, treated every 4 to 6 months with Onabotulinum 100IU.

During the entire treatment period, alternating use of $10 \mathrm{mg}$ prednisone with deflazacort $6 \mathrm{mg}$, and in 2019 , due to persistent headache and visual blurring, she underwent a new resonance with arterial and venous cranial angioresonance, with elements suggestive of Intracranial Hypertension (IH). Currently, the patient is undergoing surgical programming for facial nerve decompression bilaterally and undergoing treatment for $\mathrm{IH}$.

\section{Material and Methods}

A bibliographic review of the Melkersson-Rosenthal Syndrome was carried out, a medical record survey and interview with the patient by telephone contact and message application, since the patient lives in the interior of Espírito Santo.

\section{Discussion}

SMR is characterized by the recurrent orofacial edema and facial paralysis and plicated tongue [14], characteristics present in the case. We did not find, in the literature, cases associating SMR with facial hemispasm and IH. We emphasize the importance of insisting on biopsy, in order to document the syndrome and institute appropriate therapy, based on prolonged corticosteroid therapy. Unresponsive cases are referred for surgical treatment of facial nerve decompression, bilaterally [14]. We believe that the patient's weight gain (BMI of 27.1 to 30.8 after 15 years of treatment), resulting from prolonged use of corticosteroids, may have led to the Intracranial Hypertension syndrome $[15,16]$.

\section{Conclusion}

In the present case, we highlight the treatment of one of the late complications of peripheral facial paralysis, which consists of facial hemispasm, currently amenable to symptomatic treatment with intramuscular injections of botulinum toxin in the most reactive muscles. We also emphasize the importance of monitoring indirect causes of chronic corticosteroid therapy, such as IH resulting from overweight and obesity. 


\section{References}

1. Melkersson E (1928) A case of recurrent facial paresis in connection with angioneurotic edema. Rev Hygiea 90: 737-741.

2. Rosenthal C (1931) Clinical-hereditary contribution to constitutional pathology: common occurrence of facial paralysis (recurrent family member), angioneurotic facial edema and plicated tongue in families with arthritis. Rev Z Neurol Psychiatr 131: 475-501.

3. García AG, Barbolla ID, Sifuentes WAG, Pena JLP (2017) Miescher syndrome: An uncommon cause of recurrent swelling of the lips. Rev Reumatol Clin 13(6): 363-364.

4. Martínez ML, Defez JMA, García LJP, Villaescusa MTL, Vázquezet RM, et al. (2012) Granulomatous cheilitis. Presentation of 6 cases and review of the literature. Rev Actas Dermosifiliogr 103(8): 718-724.

5. Lüscher E (1949) Melkersson-Rosenthal syndrome. Schweiz Med Wschenschr 79(1): 1-3.

6. Nossa LMB, Costa AL, Marback RL (2001) Melkersson-Rosenthal syndrome: a clinical-pathological study of a case. Arq Bras Oftalmol $64(6)$.

7. Glickman LT, Gruss JS, Birt BD, Dang NK (1992) The surgical management of melkersson-rosenthal syndrome. Plast Reconstr Surg 89(5): 815-821.
8. Ang KL, Jones NS (2002) Melkersson-Rosenthal syndrome. J Laryngol otol 116(5): 386-388.

9. Greene RM, Rogers RS (1989) Melkersson-Rosenthal syndrome: A review of 36 patients. J Am Acad Dermatol 21(6): 1263-1270.

10. Vilela DSA (2002) Melkersson-Rosenthal syndrome: case report and literature review. Rev Bras Otorrinolaringol 68(5): 755-760.

11. Soares ECS (2006) Melkersson-Rosenthal syndrome: case report. Rev Cir Traumatol 6(1): 29-36.

12. Carvalho VAS (2020) Unilateral facial palsy: clinical aspects and main treatments. Rev Brazilian Journal of Health (3)2: 1761-1765.

13. Alexander RW, James RB (1972) Melkersson-rosenthal syndrome: review of literature and report of case. J Oral Surg 30(8): 599-604.

14. Gonçalves DU, Castro MM, Galvão CP, Brandão AZR, Castro MCM, et al. (2007) Granulomatous cheilitis associated with Melkersson-Rosenthal syndrome. Bras J Otorrinolaringol 73(1): 132-133.

15. Cairns RJ (1961) Melkersson Rosenthal syndrome. Proc R Soc Med 54(3): 217.

16. Hornstein OP, Stosiek N, Schönberger A, Stosiek MM (1987) Classification and clinical variation of melkersson-rosenthal syndrome. Rev Z Hautkr 62(20): 1453-1466.

For possible submissions Click below: 